\title{
Metal nanoparticles-based nanoplatforms for colorimetric sensing: A review
}

https://doi.org/10.1515/revac-2021-0122

received October 17, 2020; accepted January 07, 2021

\begin{abstract}
With the progress of analysis technology and nanotechnology, colorimetric detection has become one of the research hotspots in the field of analytical chemistry. Compared with traditional detection methods, the colorimetric method has many advantages, such as high sensitivity, good selectivity, convenience and fast, as well as low cost. In recent years, metal nanoparticles have been introduced into colorimetry, making the research and application of colorimetry develop rapidly. In this work, we summarize the usual colorimetric detection methods based on metal nanoparticles-based nanozymes and their applications in the last five years. We hope that this work will help readers understand the mechanism and practical application value of nanozyme-based colorimetric biosensors. Meanwhile, this work may give some hints and references for future colorimetric detection research to promote the application and development of nanozyme-based colorimetry in biomedical and environmental analysis.
\end{abstract}

Keywords: metallic nanoparticles, nanozyme, colorimetric, biosensing

\section{Introduction}

Colorimetry is a method to determine the content of metric components by comparing or measuring the color depth of the solution of colored substances. Compared with other detection methods, the colorimetric method is more intuitive. Some results can even be directly observed with the naked eye, and the target can be detected without the help of sophisticated instruments [1-3]. In recent years,

\footnotetext{
* Corresponding author: Li Wang, College of Chemistry, Jilin Normal University, Siping 136000, China, e-mail: liwang@jlnu.edu.cn Ning Xu, Shuang Jin: College of Chemistry, Jilin Normal University, Siping 136000, China
}

colorimetry has been developing rapidly and used widely. The colorimetry based on metal nanoparticles (NPs) has been a hot topic. These methods are applied to biosensors [4-6], medical diagnosis [7], environmental management [8], and many other aspects. The combination of nanomaterials and colorimetry gives new vitality to traditional colorimetry, which makes colorimetry have relatively low detection limit and high sensitivity, and the real accurate analysis is achieved. The introduction of metal NPs broadens the field of vision and leads the new research direction to develop colorimetry.

It has been found that $\mathrm{Fe}_{3} \mathrm{O}_{4}$ NPs have a catalytic activity similar to horseradish peroxidase in 2007 [9], which were call nanozymes. In subsequent studies, researchers found that some other metals or metal oxide NPs, such as $\mathrm{Au}, \mathrm{Ag}, \mathrm{Pt}, \mathrm{Cu}$, and others also have similar enzymatic catalytic activity [10-12]. The appearance of nanozymes has solved many academic problems and influences many research fields. With the deepening of research, scientists found that some metal nanomaterials after processing or modification can also show enzyme-like catalytic activity. For example, azacrown ether has been used to modify the surface of gold nanoparticles (AuNPs), and the catalytic function of enzymes could be simulated after chelation. Therefore, many experimental studies based on metal NPs had been carried out, and many materials with excellent nanozyme activity had been discovered $[13,14]$. The colorimetric methods, which are near related to nanozyme have been developed to prepare colorimetric materials with useful properties, which were utilized for the colorimetric detection of various analytes.

In the past five years, there have been a lot of reports on colorimetry, which are the latest achievements of colorimetry and the foundation for its further development. It is necessary to make a systematic summary of these findings. It not only enables us to have a deep understanding of colorimetric detection, but also gives us immense help and inspiration for our future work. In this work, the research progress of colorimetry based on metal NP-based nanozymes in recent five years is summarized. The colorimetry applications of different metal NPs are introduced 
and discussed. The development status of colorimetry is presented from many fields.

\section{Colorimetric detection based on Au NPs}

$\mathrm{Au}$ is one of the most commonly used metals in colorimetry. AuNPs have high absorption extinction coefficient and high sensitivity, which can be modified to obtain potential nanozymes with high catalytic activity [15,16].

AuNPs can be used to detect heavy metal ions. For example, Du et al. tested $\mathrm{Hg}^{2+}$ by using the mechanism that prevented melamine from causing AuNPs aggregation in an aqueous solution [17]. The linear range was $50-250 \mathrm{nM}$ and the detection limit was $50 \mathrm{nM}$. Liu et al. directly detected $\mathrm{Hg}^{2+}$ in solution with single AuNPs [18]. They used oligonucleotides to modify $\mathrm{Hg}^{2+}$. Due to the hybridization of the oligonucleotide, AuNPs aggregated in the presence of $\mathrm{Hg}^{2+}$, resulting in the color of solution change. The change of color was proportional to the concentration of $\mathrm{Hg}^{2+}$, and the detection limit was $1.4 \mathrm{pM}$.

Kanamycin may be contained in milk. The glycosides on kanamycin are specific to AuNPs, so they can interact with each other, which induces the aggregation of kanamycin, as shown in Figure 1a $[19,20]$. These changes resulted in the properties of AuNPs changing intuitively,

(a)

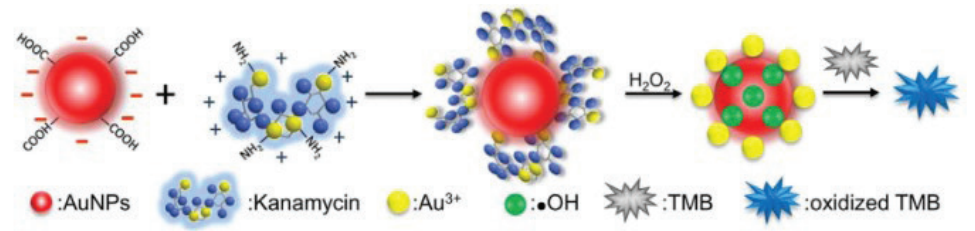

(b)

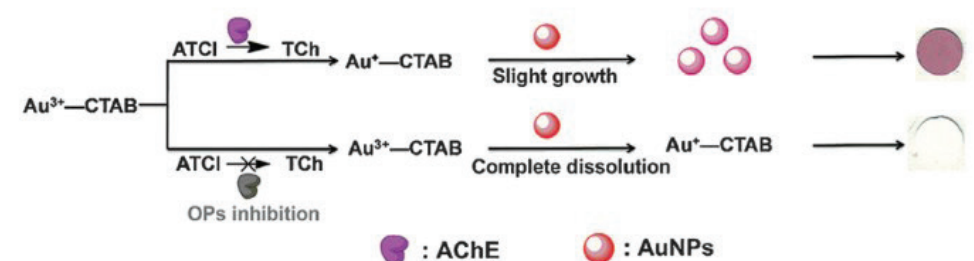

(c)

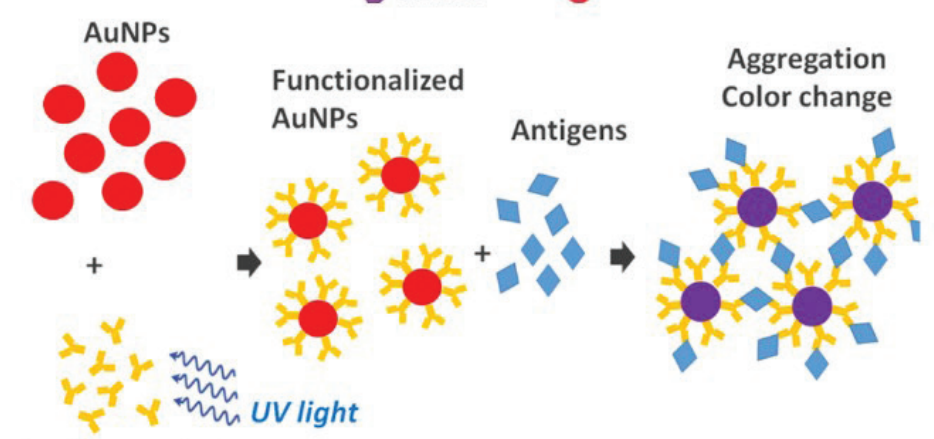

Anti Human IgG

(d)

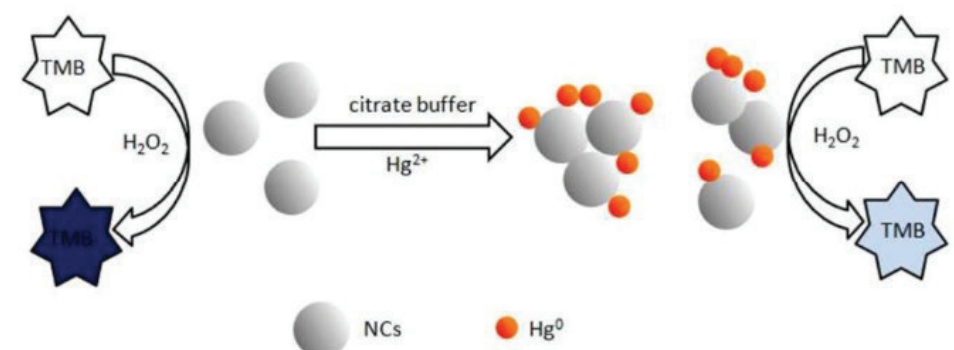

Figure 1: (a) Schematic diagram of AuNPs-based colorimetric detection of kanamycin. Reprinted image with permission from Ref. [20], Copyright 2016, Elsevier B.V. (b) Schematic diagram of OPs colorimetric analysis based on AuNPs dissolution. Reprinted image with permission from Ref. [22], Copyright 2016, Elsevier B.V. (c) AuNPs-based IgG detection scheme. Reprinted image with permission from Ref. [32], Copyright 2018, American Chemical Society. (d) The mechanism of $\mathrm{Hg}^{2+}$ detected by DNA-Ag/Pt NCs. Reprinted image with permission from Ref. [42], Copyright 2016, Royal Society of Chemistry. 
so that kanamycin can be quantitatively detected by calculation. The detection line was $73.1 \mathrm{nM}$ [19] and $288 \mathrm{nM}$ [20], respectively.

Organophosphorus pesticide (OP) pollution has serious adverse effects on human health and the environment. They are not easily found in the soil, so detecting them needs high sensitivity and selectivity. AuNPs play an essential role in the detection of parathion. The combination of phosphorus with citric acid [21], $\mathrm{Au}^{3+}$-hexadecyl trimethyl ammonium bromide (Au-CTAB) [22], fatty acid [23], cysteine [24], single-stranded DNA [25], and other substances exhibited potential activity to inhibit the aggregation of AuNPs, resulting in the color of system unchanged. Therefore, AuNPs can be modified with the materials mentioned above to detect phosphate-containing materials, as shown in Figure 1b. The detection method using the modified AuNPs was simple and useful for detecting general pesticides and many organic pesticides.

The colorimetry based on AuNPs can be used to prepare a large number of highly selective biosensors for the detection of biomolecules such as proteins [26], sugars [27], lipids [28], and neurotransmitters [29,30]. For example, Huo et al. found that the adenosine triphosphate (ATP) aptamer complex has a strong protective effect against salt-induced aggregation of unmodified AuNPs [31]. Therefore, an adaptive ATP colorimetric sensor with high sensitivity and selectivity was developed using the unmodified AuNPs as a probe. In the range of 50-1000 nM, the logarithmic concentration of ATP had a good linear relationship with absorbance. Iarossi and co-workers proposed an AuNPs-based colorimetric immune sensor, which could detect human immunoglobulin $\mathrm{G}$ (IgG) in the human body [32], and the mechanism is shown in Figure 1c. The positive IgG reaction ranges from 50 to $500 \mathrm{ng} / \mathrm{mL}$. Borghei et al. established a simple and sensitive colorimetric biosensor for detecting cancer cells based on the principle of adaptor receptor interaction [33]. The linear response for MCF-7 cells in a concentration range from 10 to $10^{5}$ cells was obtained with a detection limit of 10 cells. Almudena and co-workers also used AuNPs to detect nerve agent simulators with visual and intuitive results. It can be founded from the above applications that AuNPs have a wide range of applications for the fabrication of colorimetric biosensors, enabling efficient detection of nutrients, biotoxins and even cancerous cells in vivo [34].

AuNPs have been used as signal recorders for decades. However, due to the limitations of the inherent technology, how to improve the detection sensitivity of AuNPs substantively is still a considerable challenge [35,36]. Therefore, many methods have been explored to increase the sensitivity and activity of AuNPs. For example,
Gao et al. developed unique dual-function AuNPs to circumvent this limitation by coating conventional AuNPs with ultrathin platinum skin at ten atomic layers (Au@Pt NPs) [37]. The nuclear power source of Au@Pt NPs retained the initial plasma activity of the AuNPs and had ultrahigh catalytic activity activated by the Pt shell. The visual detection limit of LFAs was about $2 \mathrm{ng} / \mathrm{mL}$.

In recent years, the nanomaterials synthesized by using DNA as a template have been widely used. These materials have advantages, including simple synthesis, precise size control, and good biocompatibility [38-40]. More importantly, no additional functionalization of the DNA template material is required to construct the biosensor. Zheng et al. used DNA as a template to synthesize silver/platinum bimetal nanoclusters (DNA-Ag/Pt NCs), which effectively enhanced the catalytic activity of peroxides of NPs. The synthesized bimetal nanoclusters were applied for the detection of proteins, realizing more efficient detection [41]. In the range of 1-50 nM, there was a linear relationship between the absorption intensity and human thrombin concentration. The detection limit was $2.6 \mathrm{nM}$. Wu et al. further found that the peroxidase activity of DNA-Ag/Pt NCs could be selectively inhibited by $\mathrm{Hg}^{2+}$ as shown in Figure 1d. Based on this principle, a colorimetric detection method for $\mathrm{Hg}^{2+}$ was established. The detection limit was $5.0 \mathrm{nM}$ and the linear range was $10-200 \mathrm{nM}$. This method not only had high selectivity, but also reduced the cost of detection [42]. Based on the same principle, they also used DNA-Ag/Pt NCs for the colorimetric detection of L-cysteine [43]. The detection limit was $2.0 \mathrm{nM}$, and the linear range was $5.0-500 \mathrm{nM}$. The high peroxidaselike activity of DNA-Ag/Pt NCs was not affected by DNA enzymes. Thus, it could be used to detect cancer markers such as DNA methyltransferase [44] and abnormally expressed MicroRNA-21 [45]. The detection limits were $0.05 \mathrm{U} / \mathrm{mL}$ [44] and $0.6 \mathrm{pm}$ [45], respectively.

Wang and co-workers doped $\mathrm{Fe}_{3} \mathrm{O}_{4}$ NPs with AuNPs to synthesize $\mathrm{Au} @ \mathrm{Fe}_{3} \mathrm{O}_{4}$ hybrid NPs by one-step solvothermal method. The synergistic effects between $\mathrm{Fe}_{3} \mathrm{O}_{4}$ NPs and AuNPs effectively enhanced the peroxidaselike activity of $\mathrm{Au} @ \mathrm{Fe}_{3} \mathrm{O}_{4}$ NPs [46]. Based on these results, they developed a colorimetric sensor, which could detect ochratoxin A (OTA) with a detection limit as low as $30 \mathrm{pg} / \mathrm{mL}$.

In 2017, Zhang et al. took advantage of the excellent self-assembly property and chemical elasticity of amyloid peptide to form AuNPs with self-assembled fiber hybrid structure. The AuNPs have excellent electrochemical and colorimetric sensing performance. Its linear response to $\mathrm{H}_{2} \mathrm{O}_{2}$ and $\mathrm{Hg}^{2+}$ ranged from 0.1-25.85 mM and 10-70 $\mu \mathrm{M}$, respectively [47]. They also applied the same technology 
to AuNCs to produce self-assembling nanofibers with motif design peptides. This change allowed AuNCs to achieve nearly 70 -fold luminescence enhancement with a quantum yield of 21.3 [48].

Transverse flow analysis (LFAs) is based on biochemical interactions of antigen-antibody or probe DNAtarget DNA hybridization. In the LFAs system, we often use various metal NPs, color latex particles, carbon NPs, quantum dots (QDs) and enzymes as markers to improve the sensitivity of detection methods [49]. LFAs has the advantages of low cost, simple operation, convenient use, quick field response, quick visual observation results and so on [50-52]. Alina et al. used AuNPs with different shapes to make immunochromatographic strips with different colored lines. This idea solved the problem that the same color of the detection and control areas of the LFAs test paper might lead to incorrect detection results. Using the T-2 toxin (T2T) as an example, an instrumental detection limit of $30 \mathrm{pg} / \mathrm{mL}$ and a working range $0.06-0.9 \mathrm{ng} / \mathrm{mL}$ were achieved in an analysis of water-organic corn extracts [53]. AgNPs have been also exploited in lateral flow assays for signal enhancement. Laura's team used both $\mathrm{Au}$ and Ag NPs to set up a multicolor multilayer transverse flow immunoassay (xLFIA). AgNPs and two kinds of AuNPs were combined as colorimetric probes to establish a visual detection method for allergen detection [54]. The xLFIA detected allergens as low as $0.1 \mathrm{mg} / \mathrm{L}$ and could easily identify allergens in commercial biscuits based on the color of the probes.

AuNPs have also been used for nucleic acids detection and biomarkers detection $[55,56]$. For example, Xun et al. proposed a simple and fast method for simultaneous detection of nucleic acids and proteins using AuNPs and horizontal flow device [57]. The method could simultaneously detect at least $0.5 \mathrm{nM}$ of target DNA and $2 \mathrm{ng} / \mathrm{mL}$ IgG within 15 min. This method had broad prospects in the field and real-time detection of disease-related circulating nucleic acids and protein biomarkers in biological fluids.

\section{Colorimetric detection based on CuNPs}

Similar to AuNPs, CuNPs are also important nanomaterials in colorimetry. Besides their catalytic activity, CuNPs can interact with many substances and affect the reactions in the system. According to these properties, CuNPs have an ample number of applications in the field of colorimetry [58-60].

Tang et al. used QDs with photocatalytic activity to detect $\mathrm{Cu}^{2+}$, as shown in Figure 2a, and the detection limit was $5.3 \mathrm{nM}$ [61]. Yin et al. used the principle that $\mathrm{Cu}^{2+}$ can catalyze the oxidation of 2,4-dinitrophenylcysteine (DNPC) in the presence of oxygen to detect it, and the maximum detection limit was $0.5 \mathrm{nM}$ [62].

In the presence of pyrophosphate, the catalytic activity of CuNPs is greatly inhibited [63]. Therefore, the activity changes of CuNPs can be used to detect the presence of pyrophosphate or alkaline phosphatase (ALP). Liu and coworkers used pyrophosphate ion to adjust the chelating cooperation between $\mathrm{Cu}^{2+}$ and bovine serum albumin (BSA), which caused the change of the luminescence phenomenon, and the pyrophosphate could be detected base on this phenomenon [64]. The linear range of this detection method was $0.16-78.1 \mathrm{mM}$, and the detection limit was $0.083 \mathrm{mM}$. Pyrophosphoric acid can inhibit $\mathrm{Cu}^{2+}$ catalyzed oxidation of 2,2'-diazobin (3-ethylbenzothiazoline-6-sulfonic acid) ammonium salt by $\mathrm{H}_{2} \mathrm{O}_{2}$. Pyrophosphatase can make pyrophosphate hydrolyze and resume its original
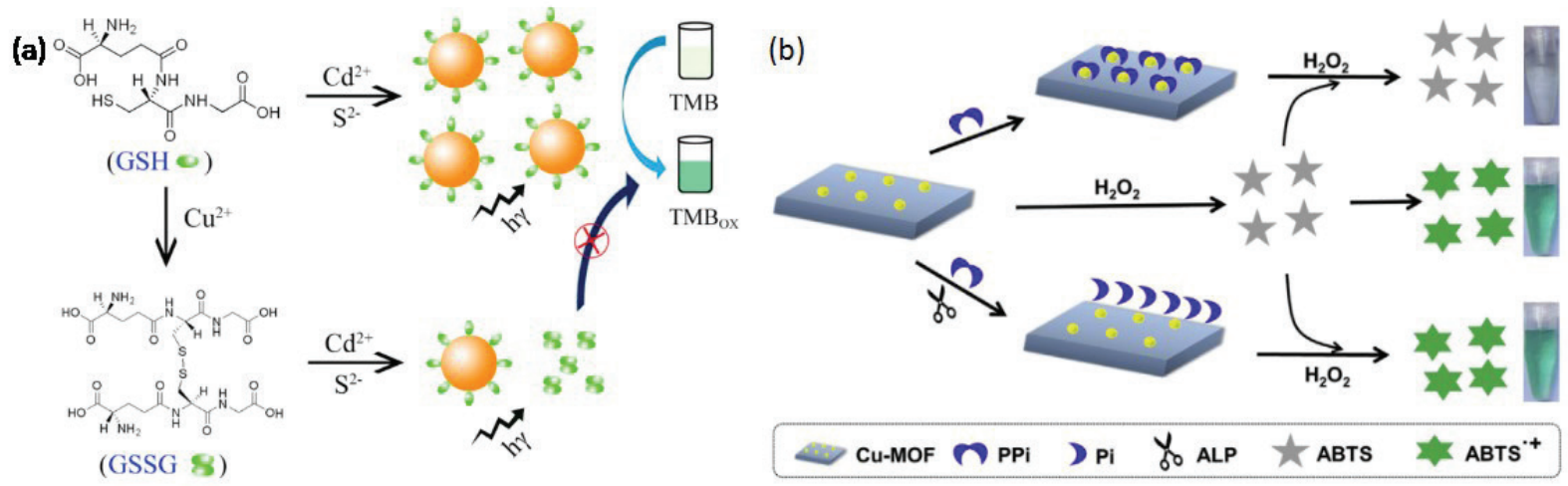

Figure 2: (a) Schematic diagram of alkaline phosphatase activity detection. Reprinted image with permission from Ref. [61], Copyright 2016, Elsevier B.V. (b) Pyrophosphate (PPi) colorimetric sensor based on BSA-AuNCs-Cu+2. Reprinted image with permission from Ref. [66], Copyright 2017, Elsevier B.V. 
catalytic oxidation reaction, so as to detect the activity of pyrophosphatase. Based on this mechanism, Zhang and co-workers detected the pyrophosphatase activity [65]. The detection limit was as low as $0.027 \mathrm{U} / \mathrm{mL}$. Wang et al. established a colorimetric detection method for alkaline phosphatase activity using Cu-MOFs as hydrogen peroxide analog and pyrophosphate as recognition elements (Figure 2b). Compared with previous method for quantitative analysis of ALP, this method was simple and intuitive, with high sensitivity and good sensing performance in serum samples [66]. The detection limit is $0.19 \mathrm{U} / \mathrm{L}$.

\section{Colorimetric detection based on FeNPs}

As one of the earliest metal NPs with peroxidase activity, $\mathrm{Fe}_{3} \mathrm{O}_{4}$ NPs have long been used in colorimetric detection
[67-69]. In the subsequent studies, it was found that not only $\mathrm{Fe}_{3} \mathrm{O}_{4}$ NPs, but also FeNPs and its various oxides could simulate the activity of enzymes and serve as catalysts. After the experimental investigation, the researchers applied them to colorimetric detection. For example, Wang et al. proposed a colorimetric label-free detection method based on Fe-MIL-88A (a Fe-based MOF material) to simulate the activity of enzymes [70]. This method is used for colorimetric detection, which can detect $\mathrm{H}_{2} \mathrm{O}_{2}$, glucose, and biomolecules. This adaptor sensing strategy could be universally applied to detect a series of environmental factors or biomolecules (Figure 3a). The limit of detection of $10 \mathrm{nM}$ could be achieved with naked eyes.

$\mathrm{Lu}$ et al. reported a multifunctional biosensor platform for sensitive $\mathrm{H}_{2} \mathrm{O}_{2}$ and glucose colorimetric detection using an asymmetric hematite silica mixture of Janusy$\mathrm{Fe}_{2} \mathrm{O}_{3} / \mathrm{SiO}_{2} \mathrm{NPs}$ (JFSNs) (Figure 3b) [71]. The results showed that JFSNs had inherent peroxidase-like catalytic activity. JFSNs nanozyme can be used over a wider range of $\mathrm{pH}$

(a)
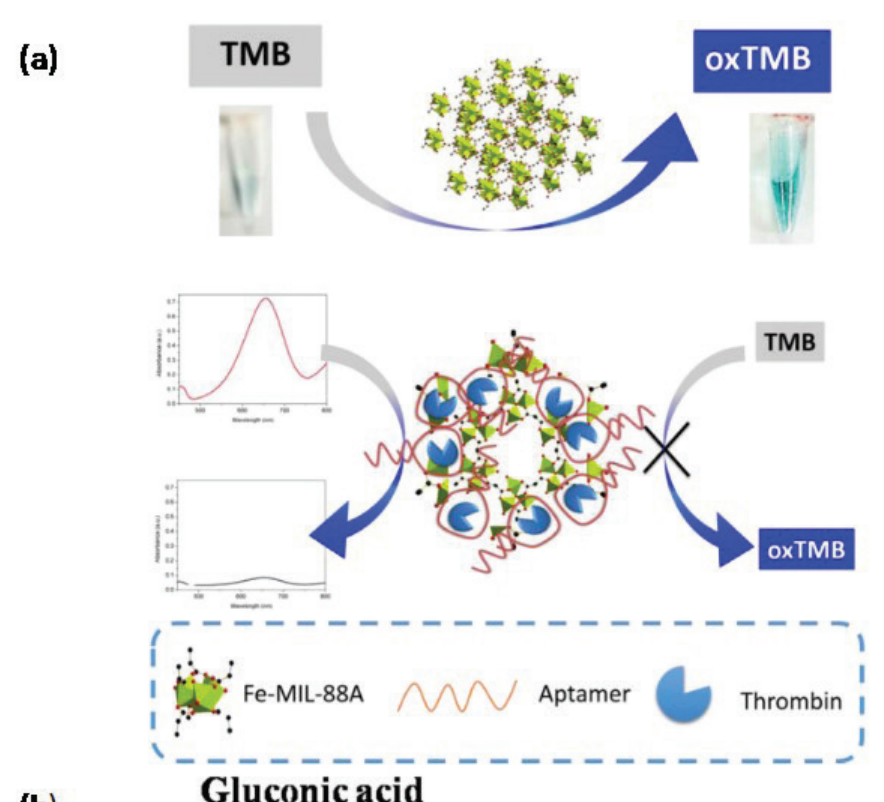

(b)

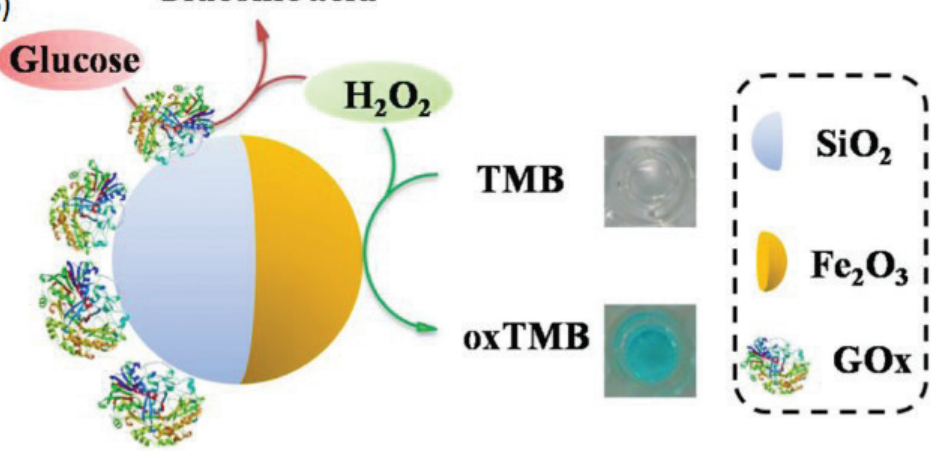

Figure 3: (a) Schematic diagram of Fe-MIL-88A‘s sensing mechanism for thrombin colorimetric detection. Reprinted image with permission from Ref. [70], Copyright 2016, Elsevier B.V. (b) Schematic diagram of biosensor using GOx-JFSNs to detect $\mathrm{H}_{2} \mathrm{O}_{2}$ and glucose. Reprinted image with permission from Ref. [71], Copyright 2015, American Chemical Society. 
(a)

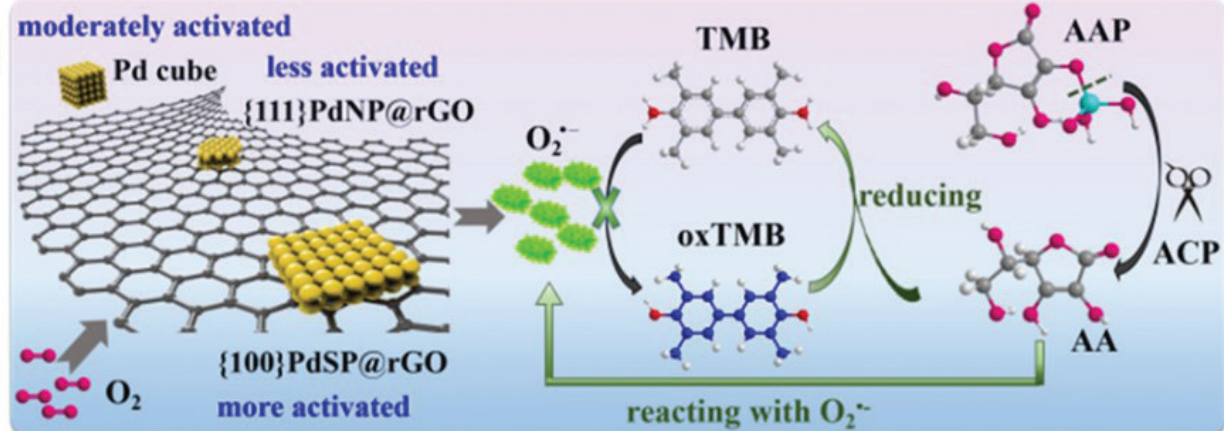

(b)

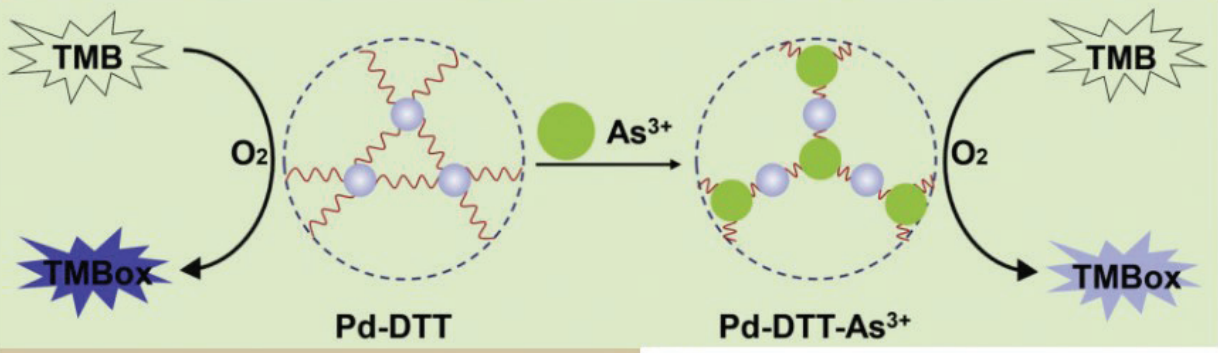

(c)

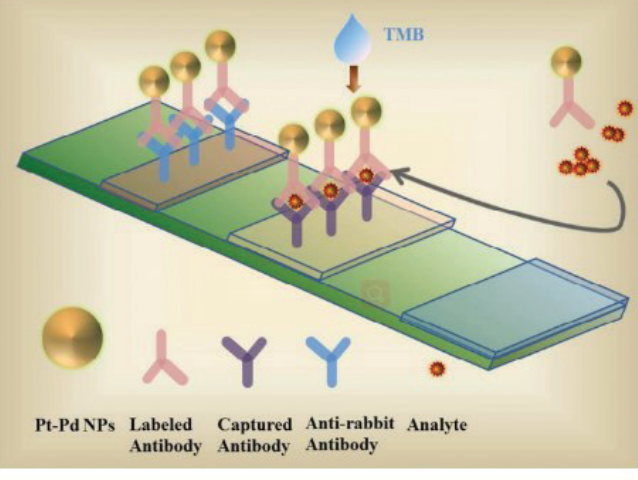

(d)

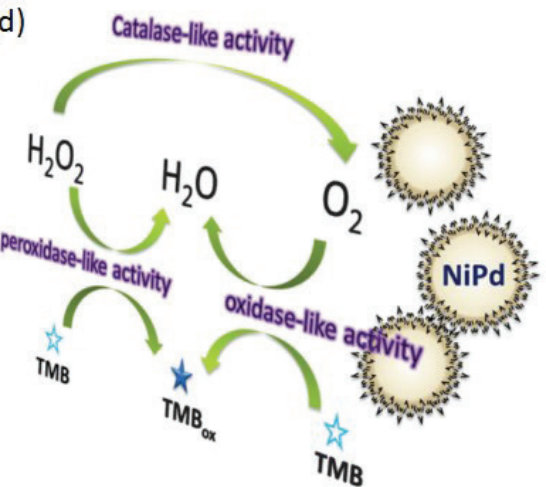

Figure 4: (a) Schematic diagram of oxidative activity of various Pd nanomaterials in the catalytic TMB oxidation. Reprinted image with permission from Ref. [73], Copyright 2019, American Chemical Society. (b) Schematic diagram of As ${ }^{3+}$ mechanism of Pd-DTT colorimetric analysis of simulated activity inhibition of polylactic acid induced oxidase. Reprinted image with permission from Ref. [77], Copyright 2019, Elsevier B.V. (c) Schematic diagram of Pt-Pd NPs immunochromatography bands for the detection of p53 protein. Reprinted image with permission from Ref. [79], Copyright 2016, American Chemical Society. (d) Schematic diagram of the activity of NiPd-HNPs trienzyme simulation. Reprinted image with permission from Ref. [80], Copyright 2016, Royal Society of Chemistry.

and temperature than the natural enzymes and are more stable over time. Due to its multi-component and synergistic multifunctional nanostructure, it is able to perform multiple tasks in a single nanosystem. The linear range was 1-100 $\mu \mathrm{M}$, and the detection limit was $10.6 \mathrm{nM}$.

\section{Colorimetric detection based on other metal NPs}

Besides the above-introduced metal NPs, many other metal NPs are also commonly used for colorimetric detection. For example, Pt and Pd are also common metal nanozyme. Wei et al. used BSA as a nucleation template to synthesize Pt-based peroxidase with an average diameter of $2.0 \mathrm{~nm}$, and detected $\mathrm{Hg}^{2+}$ through peroxidase activity simulation of metal NPs. The realized $\mathrm{Hg}^{2+}$ detection limit was found to be $7.2 \mathrm{nM}$, with a linear response range of 0-120 nM [72]. Chen and co-workers reported that two-dimensional Pd nanoplates enclosed by $\{100\}$-facets [\{100\}PdNP@rGO] exhibit substantially enhanced intrinsic oxidase-like activities relative to the $\{111\}$-facets ones and Pd nanocubes in the catalytic 3,3',5,5'-tetramethylbenzidine (TMB) chromogenic reaction (Figure 4a) [73]. Taking ascorbic acid 2-phosphoric acid as substrate and converting to ascorbic acid in the presence of acid phosphatase (ACP), ACP can be efficiently detected without destroying $\mathrm{H}_{2} \mathrm{O}_{2}$. The linear relationship was good within the range of 0.01-6.0 $\mathrm{mU} / \mathrm{mL}$, and the detection limit was 
$8.3 \mu \mathrm{U} / \mathrm{mL}$. This method is superior to most of the reported methods and can be applied to the high precision determination of serum samples.

Pd nanocubes (PdNCs) showed peroxidase activity, which was inhibited in the presence of sulfur ions. Based on this principle, a colorimetric detection method for sulfur ions was established [74]. Similarly, PdNPs also has this catalytic activity and can be used to quantitatively detect cysteine and homocysteine [75]. After the modification with histidine (His), PdNPs exhibited significantly improved simulation activity due to their good physicochemical properties, including small size and good hydrophilicity. Wenchi et al. proposed a new and efficient colorimetric method for $\mathrm{Ag}^{+}$detection based on histidinemediated PdNPs with adjustable peroxide activity. They could be used to sensitively detect $\mathrm{Ag}^{+}$with a linear scope of 30-300 nM and detection limit of 4.7 nM [76]. Xu's group measured $\mathrm{As}^{3+}$ in the drinking water and river water (as shown in Figure 4b) based on the oxidative catalytic activity of Pd NPs (Pd-DTT) coated with dithiopropanol, which showed very high sensitivity [77]. The linear range was $33 \mathrm{ng} / \mathrm{L}-333.3 \mu \mathrm{g} / \mathrm{L}$, and the detection limit was $35 \mathrm{ng} / \mathrm{L}$.

Atrazine is an herbicide widely used. However, the Environmental Protection Agency (EPA) has issued a warning about Atrazine because of the reports of its potential harm to animals and humans. Therefore, it is very important to develop an effective method to detect herbicide residues. Pt-Pd bimetallic NPs (Pt-Pd NPs) can bind directly to a primary antibody and detect Atrazine more efficiently and simply than ELISA that requiring a secondary antibody. The detection limit is $0.5 \mathrm{ng} / \mathrm{mL}$ [78]. Tao et al. reported an immunochromatographic detection band based on Pt-Pd NPs, and the detection process is shown in Figure 4c, which can intuitively and quantitatively detect $\mathrm{p} 53$ protein [79]. The method had a detection limit of $0.05 \mathrm{ng} / \mathrm{mL}$ with the linear range of 0.1-10 ng/mL. Compared with the traditional test strip based on color gold colloid, the sensitivity was improved by 2000 times.

Wang et al. proved that Ni-Pd hollow NPs (NiPdHNPs) had oxidase-like, peroxidase-like, and catalase-like activities. Then, they developed a simple glucose biosensor with a wide linear range (0.005-0.5 mM) and a low detection limit $(4.2 \mu \mathrm{M})$ using peroxidase as a simulation (Figure 4d) [80]. After continuous verification, it has been found that biological molecules such as ATP could be used to enhance the enzyme activity of metal NPs $[81,82]$. The colorimetric ability of materials can also be improved by wrapping metal particles into fiber morphology [83].

It should be noted Cd [84], Zr [85], Co [86], Pt [87], Zn [88], and other metal materials are rarely used in large quantities due to price or resource reasons, but they can also be used for colorimetric detection in some cases.

To get a more intuitive understanding of the different metal NPs and their colorimetric sensing applications, we present a table (Table 1).

Table 1: Comparison of the properties of different metal NPs and the application of colorimetric sensors

\begin{tabular}{|c|c|c|}
\hline Metal nanoparticles & Characteristics & Colorimetric sensor applications \\
\hline $\mathrm{Au}$ & $\begin{array}{l}\text { AuNPs have excellent optical and electronic properties, high } \\
\text { absorption extinction coefficient and sensitivity. }\end{array}$ & $\begin{array}{l}\text { Detect heavy metal ions such as } \mathrm{Hg}^{2+} \\
\text { [17,18,42,47]; } \\
\text { detect antibiotics in foods }[19,20] \text {; } \\
\text { detect parathion }[21-25] ; \\
\text { detect biomolecules }[26-34,41,43-45] \text {; } \\
\text { detect mycotoxins [46]; } \\
\text { LFAs [53,54]; } \\
\text { detect nucleic acids and biomarkers [55-57]. }\end{array}$ \\
\hline $\mathrm{Cu}$ & $\begin{array}{l}\text { CuNPs have large specific surface area, high thermal, high electrical } \\
\text { conductivity and catalytic activity. CuNPs are difficult to synthesize, } \\
\text { and they are easy to aggregate and oxidize due to their great specific } \\
\text { surface energy and reducibility. }\end{array}$ & $\begin{array}{l}\text { Detect organics }[61,62] \text {; } \\
\text { detect pyrophosphate or alkaline } \\
\text { phosphatase (ALP) [64-66]. }\end{array}$ \\
\hline $\mathrm{Fe}$ & $\begin{array}{l}\text { FeNPs have good activity and specific surface area. However, they } \\
\text { have poor dispersion and stability and are easy to aggregate in water. }\end{array}$ & Detect $\mathrm{H}_{2} \mathrm{O}_{2}$ and biomolecules [67-70]. \\
\hline Pt & $\begin{array}{l}\text { PtNPs have good catalytic activity, strong adsorption capacity, high } \\
\text { biocompatibility and are easy to be modified. }\end{array}$ & Detect heavy metals [72] and H2O2 [87]. \\
\hline Pd & $\begin{array}{l}\text { PdNPs are excellent hydrogen storage materials, fuel cell electrodes } \\
\text { and heterogeneous catalysis materials. }\end{array}$ & $\begin{array}{l}\text { Detect metals [77] and nonmetal ions [72]; } \\
\text { detect acid phosphatase (ACP) [73]; } \\
\text { detect biomolecules }[75,79,80] ; \\
\text { detect toxic substances [78]. }\end{array}$ \\
\hline
\end{tabular}




\section{Conclusions and outlooks}

The introduction of metal nanomaterials in recent years has led to the rapid development of colorimetry and many new colorimetry methods have been reported. This review focuses on metal NPs and summarizes the most representative colorimetric studies in the past five years. The colorimetric properties based on $\mathrm{Au}, \mathrm{Cu}, \mathrm{Fe}$, and other metal NPs and their oxides are described and discussed. The mechanisms and principles of many mature colorimetric detection methods are introduced. In addition, some typical applications involving environmental governance, biological research, clinical medicine and other aspects are listed, which fully demonstrate a mature field of colorimetry detection. A comparison of the above colorimetric methods and their applications shows that by developing colorimetric methods, we are trying to simplify complex problems to achieve simple operations and efficient detection.

Although the methods of colorimetric detection based on metal NPs are emerging in an endless way at the present stage, the researchers still need to think about how to improve the performance of metal nanomaterials on the existing technical level again, which is also the constant goal and problem in the research field. Researchers are working to improve the performance of existing metal nanomaterials, and have had some success [89-92]. Though we have found something through the research and experiment, it is still the power source to stimulate our continuous innovation to synthesize more sensitive and selective materials, or to maintain an efficient detection system under harsh conditions. The researchers have also been working hard to implement the existing colorimetric methods into convenient forms such as test strips and sensors. In addition, there are many new materials with outstanding performance, such as the perovskite materials or metal-doped composite materials. Perovskite is a ceramic oxide whose molecular formula is $\mathrm{ABO}_{3}$. The $A$ is usually rare earth metal and the $B$ is transition metal. Both A and B can be replaced by other metal ions of similar radius for forming a variety of compounds. Some studies have shown that perovskite oxide can be used for colorimetric detection by its enzyme-like activity [93]. However, up to now, the research on this aspect is still very few $[94,95]$. Whether they can show excellent performance in the field of colorimetry is waiting for us to discover and study.

In recent years, the design and synthesis of metal nanomaterials have developed rapidly, but it is necessary to develop more clean, diversified and efficient nanomaterials to construct sensitive sensors. For example, how to design novel functional metal NPs and adjust the size and morphology for broadening the application field of metal nanomaterials; how to develop new preparation techniques and methods to achieve the research and development of low-cost and high-quality metal NPs. We suggest that these issues are the key to the development of metallic nanomaterials in the next few years.

It is hoped that our work can provide some hints and help for the future research of colorimetry, so as to promote the application of colorimetry in biomedical detection and environmental analysis. We also believe that with the continuous development of science and technology, colorimetric method can constantly bring forth new ideas and solve more difficult problems.

Research funding: This work was financial supported by the National Nature Science Foundation of China (Grant No. 21505049).

Author contribution: Ning Xu: writing - original draft, writing - review and editing; Shuang Jin: writing - review and editing; Li Wang: resources, funding acquisition, supervision.

Conflict of interest: Authors state no conflict of interest.

\section{References}

[1] Nanda V, Koder RL. Designing artificial enzymes by intuition and computation. Nat Chem 2010;2:15-24.

[2] Raynal M, Ballester P, Vidal-Ferran A,van Leeuwen PWNM. Supramolecular catalysis. Part 2: artificial enzyme mimics. Chem Soc Rev. 2014;43:1734-87.

[3] Dong Z, Luo Q, Liu J. Artificial enzymes based on supramolecular scaffolds. Chem Soc Rev. 2012;41:7890-908.

[4] Kumar S, Ahlawat W, Kumar R, Dilbaghi N. Graphene, carbon nanotubes, zinc oxide and gold as elite nanomaterials for fabrication of biosensors for healthcare. Biosens Bioelectron. 2015;70:498-503.

[5] Bhattacharjee M, Pasumarthi V, Chaudhuri J, Singh AK, Nemade H, Bandyopadhyay D. Self-spinning nanoparticle laden microdroplets for sensing and energy harvesting. Nanoscale. 2016;8:6118-28.

[6] Dutta S, Mandal N, Bandyopadhyay D. Paper-based $\alpha$-amylase detector for point-of-care diagnostics. Biosens Bioelectron. 2016;78:447-53.

[7] Kim JE, Choi JH, Colas M, Kim DH, Lee H. Gold-based hybrid nanomaterials for biosensing and molecular diagnostic applications. Biosens Bioelectron. 2016;80:543-59.

[8] Che Sulaiman IS, Chieng BW, Osman MJ, Ong KK, Rashid JIA, Wan Yunus WMZ, et al. A review on colorimetric methods for determination of organophosphate pesticides using gold and silver nanoparticles. Microchim Acta. 2020;187:e131. 
[9] Mahmoudi M, Samuel EL, Catherine JM, Kenneth SS. Identification of nanoparticles with a colorimetric sensor array. ACS Sens. 2016;1:17-21.

[10] Hu L, Deng L, Alsaiari S, Zhang D, Khashab N. "Light-on" sensing of antioxidants using gold nanoclusters. Anal Chem. 2014;86:4989-94.

[11] Shang L, Dong S, Nienhaus G. Ultra-small fluorescent metal nanoclusters: Synthesis and biological applications. Nano Today. 2011;6:401-18.

[12] Liu B, Zhuang J, Wei G. Recent advances in the design of colorimetric sensors for environmental monitoring. Env Sci-Nano. 2020;7:2195-213.

[13] Manca F, Houillon FB, Pasquato L, Scrimin P. Nanozymes: Gold-nanoparticle-based transphosphorylation catalysts. Angew Chem Int Edit. 2004;43:6165-9.

[14] Liu B, Wang Y, Chen Y, Guo L, Wei G. Biomimetic twodimensional nanozymes: Synthesis, hybridization, functional tailoring, and biosensor applications. J Mater Chem B. 2020;8:10065-86.

[15] Oliveira E, Nunez C, Santos HM, Fernandez-Lodeiro J, Fernandez-Lodeiro A, Capelo JL, et al. Revisiting the use of gold and silver functionalised nanoparticles as colorimetric and fluorometric chemosensors for metal ions. Sens Actuat B-Chem. 2015;212:297-328.

[16] Chansuvarn W, Tuntulani T, Imyim A. Colorimetric detection of mercury (II) based on gold nanoparticles, fluorescent gold nanoclusters and other gold-based nanomaterials. TRACTrend Anal Chem. 2015;65:83-96.

[17] Du J, Yin S, Lin J, Bing M, Chen X. A colorimetric logic gate based on free gold nanoparticles and the coordination strategy between melamine and mercury ions. Chem Commun. 2013;49:4196-8.

[18] Liu XJ, Zhang JW, Zhang QQ, Zhao WF, Zong CH, Gai HW. Single gold nanoparticle-based colorimetric detection of picomolar mercury ion with dark-field microscopy. Anal Chem. 2016;88:2119-24.

[19] Lai C, Liu XG, Qin L, Zhang C, Zeng GM, Huang DL, et al. Chitosan-wrapped gold nanoparticles for hydrogen-bonding recognition and colorimetric determination of the antibiotic kanamycin. Microchim Acta. 2017;184:2097-105.

[20] Wang CK, Chen D, Wang QQ, Tan R. Kanamycin detection based on the catalytic ability enhancement of gold nanoparticles. Biosens Bioelectron. 2017;91:262-7.

[21] Fahimi-Kashani N, Hormozi-Nezhad MR. Gold-nanoparticlebased colorimetric sensor array for discrimination of organophosphate pesticides. Anal Chem. 2016;88;16: 8099-106.

[22] Wu S, Li DD, Wang JM, Zhao YQ, Dong SJ, Wang XY. Gold nanoparticles dissolution based colorimetric method for highly sensitive detection of organophosphate pesticides. Sens Actuat B-Chem. 2017;238:427-33.

[23] Sun JF, Guo L, Bao Y, Xie JW. A simple, label-free AuNPs-based colorimetric ultrasensitive detection of nerve agents and highly toxic organophosphate pesticide. Biosens Bioelectron. 2011;28:152-7.

[24] Balaa R, Sharmaa RK, Wangoo N. Highly sensitive colorimetric detection of ethyl parathion using gold nanoprobes. Sens Actuat B-Chem. 2015;210:425-30.

[25] Wang PJ, Wan Y, Ali A, Deng SY, Su Y, Fan CH, et al. Aptamerwrapped gold nanoparticles for the colorimetric detection of omethoate. Sci China Chem. 2016;59:237-42.
[26] Chang CC, Chen CY, Chuang TL, Wu TH, Wei SC, Liao H, et al. Aptamer-based colorimetric detection of proteins using a branched DNA cascade amplification strategy and unmodified gold nanoparticles. Biosens Bioelectron. 2016;78:200-5.

[27] Sankoh S, Thammakhet C, Numnuam A, Limbut W, Kanatharana P, Thavarungkul P. 4-mercaptophenylboronic acid functionalized gold nanoparticles for colorimetric sialic acid detection. Biosens Bioelectron. 2016;85:743-50.

[28] Hu LZ, Liao H, Feng LY, Wang M, Fu WS. Accelerating the peroxidase-like activity of gold nanoclusters at neutral $\mathrm{pH}$ for colorimetric detection of heparin and heparinase activity. Anal Chem. 2018; 90;10:6247-52.

[29] Tao Y, Lin YH, Ren JS, Qu XG. A dual fluorometric and colorimetric sensor for dopamine based on BSA-stabilized Aunanoclusters. Biosens Bioelectron. 2013;42:41-6.

[30] Wen D, Liu W, Herrmann A, Haubold D, Holzschuh M, Simon F, et al. Simple and sensitive colorimetric detection of dopamine based on assembly of cyclodextrin-modifi ed Au nanoparticles. Small. 2016;18:2439-42.

[31] Huo Y, Qi L, Lv XJ, Lai T, Zhang J, Zhang ZQ. A sensitive aptasensor for colorimetric detection of adenosine triphosphate based on the protective effect of ATP-aptamer complexes on unmodified gold nanoparticles. Biosens Bioelectron. 2016;78:315-20.

[32] larossi M, Schiattarella C, Rea I, Stefano LD, Fittipaldi R, Vecchione A, et al. Colorimetric immunosensor by aggregation of photochemically functionalized gold nanoparticles. ACS Omega. 2018;3:3805-12.

[33] Borghei YS, Hosseinia M, Dadmehr M, Hosseinkhani S, Ganjali MR, Sheikhnejad R. Visual detection of cancer cells by colorimetric aptasensor based on aggregation of gold nanoparticles induced by DNA hybridization. Anal Chim Acta. 2016;904:92-7.

[34] Martí A, Costero AM, Gaviña P, Parra M. Triarylcarbinol functionalized gold nanoparticles for the colorimetric detection of nerve agent simulants. Tetrahedron Lett. 2014;55:3093-6.

[35] Zhou W, Gao X, Liu D, Chen X. Gold nanoparticles for in vitro diagnostics. Chem Rev. 2015;115:10575-636.

[36] Wu L, Qu X. Cancer biomarker detection: recent achievements and challenges. Chem Soc Rev. 2015;44:2963-97.

[37] Gao ZQ, Ye HH, Tang DY, Tao J, Habibi S, Minerick A, et al. Platinum-decorated gold nanoparticles with dual functionalities for ultrasensitive colorimetric in vitro diagnostics. Nano Lett. 2017;17;9:5572-9.

[38] Hu R, Zhang X, Zhao Z, Zhu G, Chen T, Tan TFW. DNA nanoflowers for multiplexed cellular imaging the traceable targeted drug delivery. Angew Chem Int Ed. 2014;53:5821-6.

[39] Zhu G, Zheng J, Song E, Donovan M, Zhang K, Liu C, et al. Self-assembled, aptamer-tethered DNA nanotrains for targeted transport of molecular drugs in cancer theranostics. Proc Natl Acad Sci USA. 2013;110:7998-8003.

[40] Monson CF, Woolley AT. DNA-Templated construction of copper nanowires. Nano Lett. 2003;3:359-63.

[41] Zheng C, Zheng AX, Liu B, Zhang XL, He Y, Li J, et al. One-pot synthesized DNA-templated $\mathrm{Ag} / \mathrm{Pt}$ bimetallic nanoclusters as peroxidase mimics for colorimetric detection of thrombin. Chem Commun. 2014;50:13103-6.

[42] Wu LL, Wang LY, Xie Z], Xue F, Peng CF. Colorimetric detection of $\mathrm{Hg}^{2+}$ based on inhibiting the peroxidase-like activity of DNA-Ag/Pt nanoclusters. RSC Adv. 2016;6:75384-9. 
[43] Wu LL, Wang LY, Xie ZJ, Pan N, Peng CF. Colorimetric assay of L-cysteine based on peroxidase-mimicking DNA-Ag/Pt nanoclusters. Sens Actuat B-Chem. 2016;235:110-6.

[44] Ganjali MR, Kermani HA, Andrea M, Hosseini M, Morteza $\mathrm{H}$, Zuccheri $\mathrm{G}$, et al. A colorimetric assay of DNA methyltransferase activity based on peroxidase mimicking of DNA template $\mathrm{Ag} / \mathrm{Pt}$ bimetallic nanoclusters. Anal Bioanal Chem. 2018;410:4943-52.

[45] Fakhri N, Abarghoei S, MehdiDadmehr, Hosseini M, Sabahi $\mathrm{H}$, Ganjali MR. Paper based colorimetric detection of miRNA-21 using Ag/Pt nanoclusters. Spectrochim Acta A. 2019;227:1386-25

[46] Wang CQ, Qian J, Huang XY, Hao N, Dong XY, Wang CQ, et al. Colorimetric aptasensing of ochratoxin A using Au@Fe304 nanoparticles as signal indicator and magnetic separator. Biosens Bioelectron. 2016;77:1183-91.

[47] Zhang WS, Xi JD, Zhang YC, Su ZQ, Wei G. Green synthesis and fabrication of an electrochemical and colorimetric sensor based on self-assembled peptide-Au nanofibril architecture. Arab J Chem. 2020;13:1406-14.

[48] Zhang WS, Lin DM, Wang HX, Li JF, Nienhaus GU, Su ZQ, et al. Supramolecular self-assembly bioinspired synthesis of lumi-nescent gold nanocluster-embedded peptide nanofibers for temperature sensing and cellular imaging. Bioconjug Chem. 2017;28,9:2224-9.

[49] Elif BB, Mustafa KS. Lateral flow assays: Principles, designs and labels. TRAC-Trend Anal Chem. 2016;82:286-306.

[50] Taranova NA, Berlina AN, Zherdev AV, Dzantiev BB. "Traffic light" immunochromatographic test based on multicolor quantum dots for the simultaneous detection of several antibiotics in milk. Biosens Bioelectron. 2015;63:255-61.

[51] Fu QQ, Liang JJ, Lan CF, Zhou KN, Shi CY, Tang Y. Development of a novel dual-functional lateral-flow sensor for on-site detection of small molecule analytes. Sens Actuat B-Chem. 2014;203:683-9.

[52] Yu CY, Ang GY, Chua AL, Tan EH, Lee SY, Falero-Diaz G, et al. Dry-reagent gold nanoparticle-based lateralflow biosensor for the simultaneous detection of Vibrio choleraeserogroups 01 and 0139. J Microbiol Meth. 2011;86:277-82.

[53] Alina VP, Alexandr EU, Zherdev AV, Dzantiev BB. Gold nanoparticles of different shape for bicolor lateral flow test. Anal Biochem. 2019;568:7-13.

[54] Anfossi L, Di Nardo F, Russo A, Cavalera S, Giovannoli C, Spano G, et al. Silver and gold nanoparticles as multichromatic lateral flow assay probes for the detection of food allergens. Anal Bioanal Chem. 2019;411:1905-13.

[55] Paola V, Pier PP. Gold nanoparticles for naked-eye DNA detection: smart designs for sensitive assays. RSC Adv. 2013;3:19181-90.

[56] Devi RV, Mukesh D, Rama SV. Nanomaterials for early detection of cancer biomarker with special emphasis on gold nanoparticles in immunoassays/sensors. Biosens Bioelectron. 2015;68:688-98.

[57] Xun M, Anant G, Xu H, Baloda M, He YQ, Liu GD. Simultaneous detection of nucleic acid and protein using gold nanoparticles and lateral flow device. Anal Sci. 2014;30:637-42.

[58] Wang SQ, Deng WF, Yang L, Tan M, Xie J, Yao Z. Copper-based metal-organic framework nanoparticles with peroxidase-like activity for sensitive colorimetric detection of staphylococcus aureus. ACS Appl Mater Inter. 2017;92:24440-5.
[59] Soomro RA, Nafady A, Sirajuddin, Memon N, Sherazi $\mathrm{TH}$, Kalwar NH. L-cysteine protected copper nanoparticles as colorimetric sensor for mercuric ions. Talanta. 2014;130:415-22.

[60] Chakrapani V, Ahmed KBA, Kumar VV, Ganapathy V, Anthony SP, Anbazhagan V. A facile route to synthesize casein capped copper nanoparticles: an effective antibacterial agent and selective colorimetric sensor for mercury and tryptophan. RSC Adv. 2014;4;63:33215-21.

[61] Tang SR, Wang ML, Li Z], Tong P, Chen Q, Li GW, et al. A novel sensitive colorimetric sensor for $\mathrm{Cu}^{2+}$ based on in situ formation of fluorescent quantum dots with photocatalytic activity. Biosens Bioelectron. 2017;89:866-70.

[62] Yin K, Li BW, Wang XC, Zhang WW, Chen LX. Ultrasensitive colorimetric detection of $\mathrm{Cu}^{2+}$ ion based on catalytic oxidation of L-cysteine. Biosens Bioelectron. 2015;64:81-7.

[63] Yang JJ, Zheng L, Wang Y, Li W, Zhang JL, Gu JJ, et al. Guaninerich DNA-based peroxidase mimetics for colorimetric assays of alkaline phosphatase. Biosens Bioelectron. 2016;77:549-56.

[64] Liu JM, Cui ML, Jiang SL, Wang XX, Lin LP, Jiao L, et al. BSA-protected gold nanoclusters as fluorescent sensor for selective and sensitive detection of pyrophosphate. Anel. Methods. 2013;5:3942-7.

[65] Zhang LL, Li M, Qin YF, Chu ZD, Zhao SL. A convenient label free colorimetric assay for pyrophosphatase activity based on a pyrophosphate-inhibited $\mathrm{Cu}^{2+}-\mathrm{ABTs}-\mathrm{H}_{2} \mathrm{O}_{2}$ reaction. Analyst. 2014;139:6298-303.

[66] Wang CH, Gao J, Cao YL, Tan HL. Colorimetric logic gate for alkaline phosphatase based on copper (II)-based metal-organic frameworks with peroxidase-like activity. Anal Chim Acta. 2018;1004:74-81.

[67] Ni PJ, Sun YJ, Dai HC, Lu WD, Jiang S, Wang YL, et al. Prussian blue nanocubes peroxidase mimetic-based colorimetric assay for screening acetylcholinesterase activity and its inhibitor. Sens Actuat B-Chem. 2017;240:1314-20.

[68] Liu JM, Wang XX, Jiao L, Cui ML, Lin LP, Zhang LH, et al. Ultrasensitive non-aggregation colorimetric sensor for detection of iron based on the signal amplification effect of $\mathrm{Fe}^{3+}$ catalyzing $\mathrm{H}_{2} \mathrm{O}_{2}$ oxidize gold nanorods. Talanta. 2013;116:199-204.

[69] Wu SY, Huang H, Feng X, Du CC, Song WB. Facile visual colorimetric sensor based on iron carbide nanoparticles encapsulated in porous nitrogen-rich graphene. Talanta. 2017;167:385-91.

[70] Wang Y, Zhu Y], Binyam A, Liu MS, Wu YN, Li FT. Discovering the enzyme mimetic activity of metal-organic framework (MOF) for label-free and colorimetric sensing of biomolecules. Biosens Bioelectron. 2016;86:432-8.

[71] Lu C, Liu X], Li YF, Yu F, Tang LH, Hu Y], et al. Multifunctional janus hematite-silica nanoparticles: Mimicking peroxidaselike activity and sensitive colorimetric detection of glucose. ACS Appl Mater Inter. 2015;7:15395-402.

[72] Li W, Chen B, Zhang HX, Sun YH, Wang J, Zhang LL, et al. BSA-stabilized Pt nanozyme for peroxidase mimetics and its application on colorimetric detection of mercury(II) ions. Biosens Bioelectron. 2015;66:251-8.

[73] Chen CX, Liu WD, Ni PJ, Jiang YY, Zhang CH, Wang B, et al. Engineering two-dimensional $\mathrm{Pd}$ nanoplates with exposed highly active $\{100\}$ facets toward colorimetric acid phosphatase detection. ACS Appl Mater Inter. 2019;11:47564-70. 
[74] Wang Y, Zhang P, Liu L, Xue F, Liu MC, Li L, et al. Regulating peroxidase-like activity of Pd nanocubes through surface inactivation and its application for sulfide detection. New J Chem. 2019;43:371-6.

[75] Li W, Zhi X, Zhang JJ, Zhang JL, Fu Y. Colorimetric detection of cysteine and homocysteine based on an oligonucleotidestabilized Pd nanozyme. Anal Methods-UK. 2016;8:5111-6.

[76] Zhang WC, Niu XH, Meng SC, Li X, He YF, Pan JM, et al. Histidine-mediated tunable peroxidase-like activity of nanosized Pd for photometric sensing of $\mathrm{Ag}^{+}$. Sens Actuat B-Chem. 2018;273:400-7.

[77] Xia XC, Wang LJ, Zou XB, Wu SW, Pan JM, Li X, et al. Highly sensitive colorimetric detection of arsenite based on reassemblyinduced oxidase-mimicking activity inhibition of dithiothreitol-capped Pd nanozyme. Sens Actuat B-Chem. 2019;298:126876.

[78] Kwon EY, Ruan XF, Wang LM, Lin YH, Du D, Van Wie BJ. Mesoporous Pd@Pt nanoparticle-linked immunosorbent assay for detection of atrazine. Anal Chim Acta. 2020;1116:36-44.

[79] Jiang T, Song Y, Du D, Liu XT, Lin YH. Detection of P53 protein based on Pt-Pd nanoparticles with enhanced peroxidase-like catalysis. ACS Sens. 2016; 1; 6: 717-24.

[80] Wang QQ, Zhang LL, Shang CH, Zhang ZQ, Dong SJ. Triple-enzyme mimetic activity of nickel-palladium hollow nanoparticles and their application in colorimetric biosensing of glucose. Chem Commun. 2016,52,5410-3.

[81] Lin YH, Huang YY, Ren JS, Qu XG. Incorporating ATP into biomimetic catalysts for realizing exceptional enzymatic performance over a broad temperature range. NPG Asia Mater. 2014;6:114-20.

[82] Shah JH, Purohit R, Singh R, Karakoti AS, Singh S. ATPenhanced peroxidase-like activity of gold nanoparticles. J Colloid Interf Sci. 2015;46:100-7.

[83] Singh R, Belgamwar R, Dhiman M, Polshettiwar V. Dendritic fibrous nano-silica supported gold nanoparticles as an artificial enzyme. J Mater Chem B. 2018;6:1600-4.

[84] Xiong YH, Chen SH, Ye FG, Su LJ, Zhang C, Shen SF, et al. Synthesis of a mixed valence state Ce-MOF as an oxidase mimetic for the colorimetric detection of biothiols. Chem Commun. 2015;51:4635-8.
[85] Hu ZM, Jiang X, Xu FJ, Jia J, Long Z, Hou XD. Olorimetric sensing of bithiols using photocatalytic UiO- $66\left(\mathrm{NH}_{2}\right)$ as $\mathrm{H}_{2} \mathrm{O}_{2}$-free peroxidase mimics. Talanta. 2016;158:276-82.

[86] Fan SS, Zhao MG, Ding LJ, Li H, Chen SG. Preparation of $\mathrm{Co}_{3} \mathrm{O}_{4}$ crumpled graphene microsphere as peroxidase mimetic for colorimetric assay of ascorbic acid. Biosens Bioelectron. 2017;89:846-52.

[87] Ding YN, Yang BC, Liu H, Liu ZX, Zhang X, Zheng XW, et al. FePt-Au ternary metallic nanoparticles with the enhanced peroxidase-like activity for ultrafast colorimetric detection of $\mathrm{H}_{2} \mathrm{O}_{2}$. Sens Actuat B-Chem. 2018;259:775-83.

[88] Liu QY, Chen PP, Xu Z, Chen MM, Ding YN, Yue K, et al. A facile strategy to prepare porphyrin functionalized $\mathrm{ZnS}$ nanoparticles and their peroxidase-like catalytic activity for colorimetric sensor of hydrogen peroxide and glucose. Sens Actuat B-Chem. 2017;251:339-48.

[89] Zhang S, Zhang XY, Su ZQ. Biomolecules conjugated metal nanoclusters: bio-inspiration strategies, targeted therapeutics, and diagnostics. J Mater Chem B. 2020;8:4176-94.

[90] Li YD, Wu H, Su Z. Enzyme-based hybrid nanoflowers with high performances for biocatalytic, biomedical, and environmental applications. Coord Chem Rev. 2020;416:213342.

[91] Liu TJ, Guo YQ, Zhang ZF, Miao ZC, Zhang XY, Su ZQ. Fabrication of hollow CUO/PANI hybrid nanofibers for non-enzymatic electrochemical detection of $\mathrm{H}_{2} \mathrm{O}_{2}$ and glucose. Sens Actuat B-Chem. 2019;286:370-6.

[92] Zhang S, Jia ZX, Liu TJ, Wei G, Su ZQ. Electrospinning nanoparticles-based materials interfaces for sensor applications. Sensors. 2019;19:3977-4001.

[93] Song LF, Zhu Y, Yang ZZ, Wang C, Lu XF. Oxidase-mimicking activity of perovskite $\mathrm{LaMnO}_{3+\bar{\delta}}$ nanofibers and their application for colorimetric sensing. J Mater Chem B. 2018;6:5931.

[94] Wang XY, Cao W, Qin L, Lin TS, Chen W, Lin SC, et al. Boosting the peroxidase-like activity of nanostructured nickel by inducing its $3+$ oxidation state in $\mathrm{LaNiO}_{3}$ perovskite and its application for biomedical assays. Theranostics. 2017;7(8):2277-86.

[95] Wang KY, Song JZ, Duan XJ, Mu JS, Wang Y. Perovskite $\mathrm{LaCoO}_{3}$ nanoparticles as enzyme mimetics: their catalytic properties, mechanism and application in dopamine biosensing. New J Chem. 2017;41:8554. 